\title{
BARNA Member Benefits Survey
}

\author{
Sarah Garry
}

BARNA Secretariat, E-mail: sgarry@kenes.com

$\mathrm{T}$ better understand the needs of our members, British Anaesthetic and Recovery Nurses Association (BARNA) undertook its first Member Benefits Survey during August 2012.

This survey was designed to conincide with the relaunch of the society so that benefits listed as most favourable by the membership could be developed in priority order, with a number of additional benefits being in place for the launch on 10 November at the BARNA Annual Conference 2012.

Despite the survey being available for completion at the height of the summer holidays, we received a $15 \%$ response rate from our members, which is average for a survey of this kind.

\section{CURRENT BARNA BENEFITS}

The results indicated that the most popular benefit with members by far is the discount to the annual conference, with over $90 \%$ of respondents indicating it is a very or extremely useful benefit.

This was closely followed by the British Journal of Anaesthetic and Recovery Nursing (BJARN), where just under $70 \%$ of respondents indicated this was very or extremely useful to them. This response has reaffirmed with BARNA the need for a quality, academic publication for our members. In light of this, we have appointed a new Co-Editor whose introduction you have read in this issue, and have increased our efforts to ensure that the material provided within the BJARN is of the highest quality.

Although the BARNA newsletter and Facebook page did not score as highly among the respondents for usefulness, we will continue to use these methods to communicate with our members regularly. We hope, however, that after our relaunch and the first edition of the new-look newsletter, which you received in
November, that in future membership surveys the newsletter will rate as a valuable part of your membership, which keeps you up to date on the educational, social and political aspects of the association, which we cannot always include in the BJARN.

\section{FUTURE BENEFITS}

Developing any new membership benefit takes time and commitment from the BARNA Committee; therefore, before undertaking these developments, the membership survey provides us with an excellent starting point to see what our members really need to help them perform their duties in the post-anaesthesia care unit (PACU) effectively.

Of the respondents, $93 \%$ felt that information relating to competency development would be a useful tool, and $92 \%$ of respondents felt that an advanced skill package for experienced staff would be useful documentation for themselves and their department.

Other key benefits, which members indicated they would like to see, were online learning material to support the competency package $(79 \%)$, a list of courses available in anaesthesia and recovery $(71 \%)$, reflective personal histories $(64 \%)$, previous audit results $(64 \%)$ and powerpoint presentations available to download $(64 \%)$.

A number of the benefits members requested are already available on the relaunched BARNA website including a detailed course listing, a number of reflective personal histories and the 2010-2011 staffing audit results. A number of other benefits requested are in development and we hope to be able to provide you with a new benefit in the form of e-learning in the members' area of the website, or policy and guidance documentation every two-three months. We will announce these new documents through our Facebook page as they become available and through the bi-monthly 
newsletter. To make sure you know as soon as benefits become available, joining us on Facebook will mean you receive the latest news and information at the click of a button without having to wait for the newsletter every two months!

\section{ANNUAL AUDIT}

In addition to viewing previous audit results online, respondents were also interested in BARNA undertaking future audits, with all the potential topic areas being very or extremely interesting to at least $75 \%$ of respondents!

This supports BARNA's thoughts that there is a real need for research within the PACU to continue to ensure the safety of both patients and staff within the hospital.

BARNA hopes to undertake a further audit during 2013, to support the work started in 2010-2011 with our first audit in staffing. More details about the audit topic and how your unit can take part will be available during the Spring of 2013.

\section{EVENTS}

We have always been impressed with the number of members who attend our annual conference. The feedback from our benefits survey indicated that there is a similar appetite for the delivery of smaller, regional study days.

The study days, which we hope will address fundemental training needs of new staff and provide refresher training for more experienced members of the team, were well received in the survey, with all three potential topics for the day being of interest to our members:

- $79 \%$ rated essential applied anatomy and physiology (airway, breathing, circulation) as very or extremely interesting;

- $86 \%$ rated the session entitled the impact of anaesthesia and surgery on system function as very or extremely interesting; and

- $86 \%$ rated the session management of system in recovery to pre-empt problems or correct if implications occur, as very or extremely interesting.

Although these events are still in their planning stages, we hope to trial some launch events during late 2013.

\section{SUMMARY}

Undertaking the member benefits survey has helped shape the work that the committee has been undertaking over the past few months in relaunching the association. The results have influenced the direction that the relaunch has taken, and has meant that the committee continues to be focused on the delivery of quality, practicably useful education for all levels within the nursing team.

We continue to welcome your feedback, either relating to the benefits we are providing, or the association as a whole. In addition, ideas for future benefits would be welcomed, along with contributions for either the BJARN, BARNA newsletter or to the many benefits we hope to produce for you in the coming months. 